\title{
INFLUENCIAS DE LAS COORDENADAS TEMPORALES SOBRE EL HONOR DEL CABALLERO MEDIEVAL
}

Eva Parra Membrives

\author{
"Sun, dû solt wizzen, daz der schilt \\ hât werdekeit und êren vil: \\ den ritter tugende niht bevilt, \\ der mi ze rehte volgen wil. \\ Die wârheit ich dich niht enhil: \\ er ist zer werlte sunder wân \\ ein hôchgemezzen vreuden zil."
}

Tan ligada a la imponente figura del caballero medieval como su armadura, su caballo o esa hermosa doncella que inspira la mayor parte de sus heroicas acciones se halla sin lugar a dudas el concepto del honor. En realidad, es precisamente la obligada demanda de ese honor, su verificación constante, su lamentable pérdida en ocasiones y las dificultades que puede llegar a entrañar su restauración lo que constituye más que ningún otro motivo la excusa predominante de los autores medievales en el momento de elaboración de atractivas aventuras caballerescas de carácter literario. Prácticamente todos los caballeros relevantes de la literatura cortesano - caballeresca alemana han visto peligrar su honor en algún momento de su carrera y han sido obligados por ello a realizar esfuerzos inusitados para enmendar sus posibles faltas, obteniendo, por cierto, en este propósito resultados muy desiguales. Importante será puntualizar ahora que como 'honor' - y esto afecta a la dama al igual que al caballero - no debe contemplarse en contextos literarios tanto la observancia auténtica, real, de una vida virtuosa, sino más bien la obtención, mediante el cumplimiento de determinadas normas y convenciones del entorno, de una fama y un prestigio sociales (TOMASEK, 1985: 67) que conviertan al caballero medieval en un miembro destacado de su comunidad. El caballero puede disfrutar así de una amplia permisividad que respalde sus actos inmorales potenciales, sin que éstos contribuyan en ninguna medida a mermar su honor - aunque siempre que estas faltas sean realizadas en la más estricta intimidad y no lleguen a trascender públicamente.

Uno de los ejemplos más significativos de esta moral tan particular que autoriza los pecados sociales negando su trascendencia - a condición de que se mantengan en secreto - puede advertirse en la continuación del Tristan de Gottfried von Straßburg elaborada por

\footnotetext{
${ }^{1}$ WINSBECKE, Lehren für den ritterlichen Kampf, Str. 17, citado por: Arentzen, J.; Ruberg, U. (eds.) (1987), Die Ritteridee in der deutschen Literatur des Mittelalters. Eine kommentierte Anthologie, Darmstadt, pág. 94
} 
Heinrich von Freiberg. En un determinado momento, los más nobles caballeros cortesanos, entre los cuales habrá de incluirse significativamente también al mismísimo Rey Arturo, conspiran para que el adulterio de Tristan con Isolde, la esposa de su tío, no pase del plano de la intimidad y no logre con ello afectar al elevado honor del joven. En la obra, Tristan se atiene a las exigencias sociales, pues in forma clandestina y en horas manifiestamente nocturnas. Sin embargo, a pesar de todos sus esfuerzos, llega a peligrar su consideración social, pues el joven y noble caballero es seriamente herido por una trampa colocada por su tío, el rey Marke, el esposo afrentado, a la puerta de la alcoba de Isolde, la dama infiel, y con ello, los crímenes de ambos - aquí en plural, pues al adulterio se suman la traición y el incesto - pueden quedar al descubierto. Curiosamente, es aquí la posible divulgación de los hechos, y no el censurable acto cometido en sí, lo que llega a causar honda preocupación en los caballeros de la Tabla Redonda. Así, el valiente Gawân, uno de los caballeros más afamados de toda la épica artúrica, frecuentemente alabado en los textos como joven de honor destacado, cuando tiene conocimiento de las heridas de Tristan, maldice la astucia de Marke al tenderle una trampa a su sobrino, lamentándose:

"Owê, Owê und immer ach!

Wie des künges Marken list

uns nû zu schaden kumen ist!"

(HEINRICH, 1887, vv. 2828-2830) ${ }^{2}$

En ningún momento, sin embargo, puede oirse al caballero amonestar a Tristan por su evidente transgresión. Esta permisividad social se torna más lúcida aún cuando los restantes caballeros de la Tabla Redonda se congregan para intentar hallar un modo de eludir la divulgación del delito de Tristan. Keie, otro de los caballeros artúricos más conocidos, sugiere como solución lo que podría denominarse 'ocultar el árbol en el bosque', es decir, propone que los caballeros presentes en la reunión se infrinjan a sí mismos heridas similares a las que presenta Tristan, arrojándose todos voluntariamente a la trampa de Marke. De este modo, las lesiones de Tristan ya no destacarían, y el adulterio no podría verificarse. Esta idea de Keie es recibida con aclamación general, y finalmente llevada a cabo:

\footnotetext{
"..."dunket ez iuch alle guot, sô mache wir ein gewuofe, einen schal und ein geruofe und rumpeln under ein ander gar, sô loufe ieglicher dar zu dem bloche listeclich und vorsnide selbe sich. Swennedes der künic wirt gewar, daz wir sîn vorsniten gar, so gewinnet er keinen arcwân zu sîner swester sun Tristan."

Diser mêre vroute sich der künic Artus innenclich
}

2 “Ay, ay, ay, y siempre ay /cómo ha conseguido la astucia del rey Marke /perjudicarnos a todos!” 
und danket Keien sâ zustunt, daz er sô listigent vunt"

(HEINRICH, 1887: vv.2876-2890) ${ }^{3}$

El entusiasmo con el que los caballeros deciden amparar un acto tan deshonroso como el cometido por Tristan sin reprochárselo en ningún momento y celebrando incluso el engaño al que van a someter a Marke, demuestra lo flexible que puede llegar a ser el concepto del honor.

Lamentablemente, no siempre la falsa moral ha de beneficiar. Si el ejemplo anterior ha confirmado que para conservar el honor únicamente es necesario cuidar una conducta públicamente oportuna, aunque en privado se burle constantemente todo concepto de integridad, ¿qué ocurrirá cuando el caballero no tenga nada que reprocharse, pero la sociedad en la que se mueve juzgue que ha incumplido las pautas de conducta? En este sentido puede mencionarse un ejemplo muy ilustrativo de la obra quizá más trascendente dentro de la épica cortesano - caballeresca alemana, Parzival, de Wolfram von Eschenbach. Aquí no será un caballero, sino una dama, la que llega a perder su honor. La escena es muy conocida, se trata del fragmento en el que Jeschute, la hermosa hermana de Erec, duerme una plácida siesta en el interior una lujosa tienda de campaña, cuando, en ausencia de su esposo Orilus, es abordada con cierta violencia por un joven y aún inconsciente, por no decir atolondrado, Parzival. La chica se resiste heroicamente a los besos y abrazos que Parzival, por razones que ahora no vienen al caso, desea imponerle. Eschenbach, el autor, subraya que, a pesar de que Jeschute era sólo una débil mujer, tiene lugar una lucha extraordinaria:

\footnotetext{
"diu vrouwe was mit wîbes wer:

ir was sîn craft ein ganez her.

Doch wart dâ ringens vil getân"
}

(WOLFRAM, 1989: 226) ${ }^{4}$

Sólo esta resistencia demuestra ya una conducta intachable por parte de la joven, que, desde luego, no se arroja en los brazos de Parzival de manera voluntaria. La fidelidad a su marido, el noble Orilus, queda demostrada para el lector. Sin embargo, de poco le sirve a la pobre Jeschute su honestidad, pues la certeza que poseen los lectores de su correcta actuación no puede extenderse al entorno de Jeschute. Cuando retorna el marido ausente, halla a la chica no muy compuesta en la tienda, y descubre, además, en la hierba huellas de la tempestuosa visita. Las apariencias insinúan que ha tenido lugar un acto deshonroso. Indiferente a las explicaciones de la joven, el esposo se siente públicamente puesto en evidencia y decide someter a la chica a un castigo ejemplar: De ahí en adelante, a Jeschute

3 "Si os parece bien a todos, hagamos ahora mucho ruido, como de una caída y lancemos unos gritos y empujémonos los unos a los otros, de manera que todos nosotros caigamos dentro de las cuchillas y nos cortemos. Cuando entonces el rey vea que todos estamos heridos, no sospechará nada de Tristán, el hijo de su hermana. De esta idea se alegró de corazón el rey Arturo y le dio las gracias a Keie, por haber sido tan astuto"

4 "La mujer sólo podía defenderse con aliento femenino, para ella, la fuerza de él era como la de todo un ejército. A pesar de ello, hubo una lucha muy intensa." 
le estará vedado despojarse jamás del camisón que la cubría durante unos pecaminosos hechos que en realidad no han ocurrido, una prenda que, andrajosa con el tiempo, señalará su penitencia de manera tan pública como lo ha sido su inexistente delito. Y Jeschute aceptará resignada su castigo. "ir kiusche unde ir wîpheit / Sîn hazzen lîden muosten" (WOLFRAM, 1989: 234), su castidad y su feminidad debieron soportar su odio, indica el autor.

Esta influencia tan extrema de la opinión pública sobre el destino de la dama y el caballero lleva a que no resulte tan sugestivo y digno de estudio qué se hace en las novelas cortesano - caballerescas para alcanzar y conservar el honor, sino más bien el cómo se lleva a cabo esta empresa. Cada una de las acciones que inicie el caballero medieval ha de seguir así un ritual determinado que coincide con las pautas de comportamiento que la sociedad ha fijado. Sólo de este modo le será posible preservar el tan ansiado honor. Y en el cumplimiento de estas reglas sociales que salvaguardan la estima pública del caballero jugará un papel fundamental el tiempo.

Como es sabido, el mundo cortesano - caballeresco, y, sobre todo, el artúrico, suele caracterizarse por una ausencia casi completa de referencias temporales. Los incidentes que se narran acontecen en un momento indeterminado que puede ubicarse tanto en el pasado como en el presente del lector medieval. Es esta atemporalidad precisamente la que dota a las historias narradas de ese halo de magia y de misterio que tan atractivos habían de resultar en la época en la que nacieron y que les hacen irradiar su encanto hasta hoy en día. Por ello llama especialmente la atención que, en ocasiones, las coordenadas temporales hayan de actuar de manera tan sobresaliente sobre el honor del caballero medieval.

Uno de los casos más conocidos en el que tiempo y honor corren parejos hasta el punto de que el incumplimiento del primero repercute negativamente sobre el segundo, conduciendo al caballero en cuestión no sólo al deshonor sino asimismo a la locura, es el de Iwein, protagonista de la novela del mismo nombre creada por Hartmann von Aue. El joven Iwein es un caballero valeroso que acaba de desposarse con la bella Laudine, cuando le pide a su amada un año de licencia. Esta separación no significa que el caballero desee, de inmediato tras la boda, perder ya de vista a su esposa. Al contrario, Iwein está profundamente enamorado, pero teme que su amor le transforme en un marido comodón, apático y ocioso, y desea ejercitarse en la aventura antes de iniciar la vida matrimonial para dejar patente al mundo su valía y prevenir toda posible crítica. Además, ni siquiera parte de él mismo la iniciativa de este alejamiento temporal, sino de su amigo Gawân, caballero, como se ve, casi omnipresente en la épica cortesano - caballeresca alemana. Tras proferir un amplio discurso acerca de la belleza de la mujer y su influencia sobre los varones, Gawân consigue intimidar a Iwein, advirtiéndole que la hermosura de una mujer puede llevar al deshonor. En una clara alusión a Erec, conocido héroe de otra obra de Hartmann von Aue, caballero que descuidó su honor dedicándose en demasía a los placeres del amor, Gawân recomienda a su amigo Iwein una continuidad en las labores propias de un caballero:

"iu hât erworben iuwer hant ein schoene wîp unde ein lant.

Sît iu nû wol geschehen sî, sô bewaret daz dâ bî 


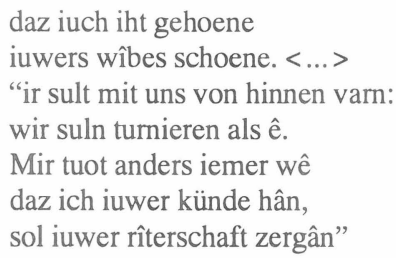

(HARTMANN, 1982: vv. 2781-2786; 2802-2805) ${ }^{5}$

Gawân aconseja una separación temporal para templar las pasiones que dominan al recién casado, no, desde luego, un divorcio ni un abandono. Por ello, será fundamental recabar el permiso de la esposa, así lo exige la normativa social:

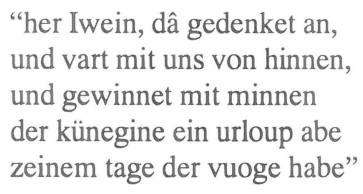

(HARTMANN, 1982, vv.2884-2888) ${ }^{6}$

Obsérvese cómo en la cita Gawân sugiere que Iwein se mantenga alejado de Laudine hasta 'un día que parezca apropiado'. A pesar de haber aconsejado a su amigo en todo lo demás, no fija el espacio temporal conveniente. Ello no es necesario. El mundo cortesano caballeresco predetermina ya cuánto ha de durar la separación entre los esposos cuando uno de los dos aún no se halla preparado para vivir en unión. Iwein, a quien se le ha brindado la oportunidad de precisar la duración que socialmente resulte más prudente y con ello demostrar que conoce y respeta las normas cortesano - caballerescas, se decide en favor de un año. Y su decisión resultará acertada, pues será aplaudida tanto por los demás personajes de la obra como por la misma Laudine. La joven, caracterizada en la novela como dama intachable, concede sin dudar, cumpliendo a la perfección con su papel, lo que se le ha requerido, pues, en efecto, un año parece ser el espacio temporal que socialmente se contempla.

Lamentablemente, de poco le sirve a Iwein su acierto al elegir la fecha de su vuelta, pues, entusiasmado con las muchas aventuras que vive, la incumple y deja transcurrir ocho meses más de lo prometido sin retornar a los brazos de su esposa. Dado que el alejamiento es demasiado prolongado, Laudine se desdice de su marido, y, acusándole de traidor, engañoso y otras muchas maldades más le hace caer en el más profundo deshonor, y, como consecuencia de esto, en la locura. Al igual que ocurriera con Jeschute, Iwein no ha traicionado en realidad a su esposa, pues su larga ausencia no significa que su amor haya

\footnotetext{
5 "Hoy ha conquistado vuestra mano una bella doncella y un gran país. Muy bien lo habéis hecho hasta ahora, pero debéis continuar de este modo. Que no os sirva de afrenta la belleza de vuestra mujer. Ahora, debéis marcharos con nosotros. Participaremos en torneos, tal como hacíamos antes. Me dolería muchísimo tener noticia de que, con vuestro matrimonio, hubiese desaparecido vuestra caballerosidad."
}

6 "Señor Iwein, pensadlo bien y marchaos con nosotros. Ganad con amor el permiso de la reina para alejaros de ella hasta un día que resulte adecuado". 
desaparecido. En todo momento, el joven ha mantenido su fidelidad. A pesar, sin embargo, de que sigue siendo aún el joven valiente y de buen corazón que había enamorado a Laudine, como no ha sabido cumplir con la exigencia social del plazo anual, Iwein no puede mantener su honor ante la sociedad.

Que la elección de un año como intervalo de alejamiento entre los esposos no es aleatoria sino responde a las expectativas sociales, puede advertirse en la frecuencia con la que se impone esta fecha en casos como el referido, es decir, cuando uno de los esposos ha de perfeccionarse o purificarse antes de merecer al otro. En la ya mencionada obra de Heinrich von Freiberg Tristan, este joven dispone asimismo del lapso de un año para consumar el matrimonio que acaba de contraer con Isolde Manos Blancas. Tristan, que, como se recordará por lo referido hace apenas unos instantes, está perdidamente enamorado de la esposa de su tío, de nombre también Isolde, toma como esposa a Isolde Manos Blancas, en un vano intento de olvidar a su verdadera amada y alejarse del pecado. Sin embargo, durante la noche de bodas, encadenados tanto su alma y su pensamiento a su amante, Tristan se revela como incapaz de consumar el matrimonio con su nueva esposa. Cuando ésta, ofendida, exige una explicación por el desinterés de Tristan, el caballero inventa una singular aventura y, de paso, pide permiso para seguir manteniendo a Isolde Manos Blancas en esa no querida virginidad:

\author{
"ein âventiure mir geshach \\ zu Weisefort in Îrlant: \\ dâ sluoc ich einen serpant \\ grôz und ungehiure, \\ der werte sich mit viure. \\ Und als ich in überwant, \\ dô het er mich sô gar vorbrant, \\ daz ich vor hitze kûme genas. \\ Ein trüebe lache nâhen was \\ bî mir; dâ senket ich mich în \\ durch genist des lebenes mîn. \\ Ez was ein wunder wunderlich \\ und wundert sîn noch hiute mich, \\ daz ich dar inne nicht ertranc, \\ wan ich unz an den helm vorsanc. \\ Und als ich was in dirre nôt, \\ der maget ich ein gelübde bôt, \\ die unseren herren Christ gebar. \\ Ich swuor ir unde lâze ez wâr: \\ swenne mir der sêlden tac betaget, \\ daz mir getrûwet würde ein maget, \\ die ich minem lîbe \\ zu vrouwen und zu wîbe \\ in rechter ê solde hân, \\ daz ich sie maget wolde lân \\ und liusch ein umbe gêndez jâr. \\ Dô ich den eit volbrâchte gar, \\ vil schiere mir zu helfe quam \\ ein schoene vrouwe wunnesam"
}


(HEINRICH, 1877: vv. 1054-1082) ${ }^{7}$

Como hiciera Iwein, Tristan demanda un año de plazo y, en efecto, le es inmediatamente concedido por su esposa sin que con ello su honor haya de sufrir. Obsérvese aquí que las circunstancias que rodean a ambos caballeros son muy diferentes. Iwein necesita afianzar su honor, pero ama mucho a su esposa y, al menos en el momento de solicitar la licencia, desearía no tener que alejarse nunca. A Tristan, Isolde Manos Blancas le es completamente indiferente y el joven así recurre a un ardid para ganar tiempo y no verse obligado a convivir con ella como su marido que es. Mientras el íntimo deseo de Iwein es un lapso de tiempo lo más breve posible, el de Tristan habrá de ser el más prolongado que pueda considerarse aceptable. Si ambos recurren al año como fecha tope, ello demuestra que se trata de un espacio temporal que puede defenderse socialmente y parece el más adecuado. Al igual que ocurriera con Iwein, es cuando Tristan incumple también esa separación anual, y, más allá de la fecha indicada, sigue sin tocar a su mujer, cuando peligrará su honor. Indignada, Isolde Manos Blancas, tan cansada de esperar como Laudine, acusa públicamente a Tristan de su crimen y provoca con ello su deshonor.

El incumplimiento de determinados plazos o espacios temporales puede así determinar, como se ve, el honor o deshonor de los personajes. Otra de las fechas más frecuentes que aparecen en las novelas cortesano - caballerescas influyendo sobre el honor del caballero o la dama serán los cuarenta días o seis semanas que se prevén para preparar un torneo, una lucha o una aventura - en el caso del caballero - o buscar a alguien que las defienda en el caso de las damas. En la obra Iwein, el mismo rey Arturo menciona esta costumbre:

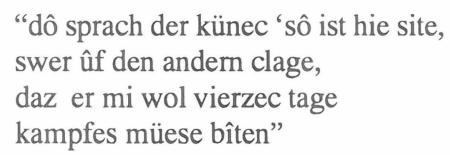

(HARTMANN, 1982: vv. 5742-5745) $^{8}$

Esta usanza de otorgar cuarenta días, que, como todas las mantenidas en el entorno cortesano - caballeresco, adquiere el valor de una ley no escrita, puede advertirse normalmente cuando el honor o de una dama o de un caballero han quedado en entredicho por algún motivo. Durante esta cuarentena, el honor cuestionado se mantiene en suspenso, y el caballero - o la dama - se encuentran en una especie de limbo social, es decir, en un lugar que no puede considerarse exactamente perteneciente al entorno cortesano caballeresco, pero tampoco del todo ajeno a él. Una vez transcurrido el tiempo en el que el

\footnotetext{
7 "Me sucedió una aventura / en Weisfort, Irlanda / Mate allí a una serpiente / grande y terrorífica/ Que se defendía con fuego /Cuando la sometí / me quemó totalmente / de modo que casi no tuve salvación / Un charco turbio se hallaba cerca / y allí me sumergí / para salvar mi vida / Fue un milagroso milagro / y aún hoy me sorprende / que no me ahogara allí mismo / Pues me hundí hasta el yelmo / Y estando en esa dificultad/ realicé una promesa /A aquélla que dio a luz a nuestro señor / Juré cumplir lo siguiente: / si llegara alguna vez el día / en que me casara con una doncella / que con mi cuerpo /habría de convertir en mujer / tras justo matrimonio/ la dejaría doncella / Y pura durante un año entero/ En cuanto juré esto / rápidamente me llegó la ayuda / en forma de una mujer bellísima"
}

8 "Y dijo el rey: Aquí es costumbre que cuando uno acusa a otro se le otorguen cuarenta días para preparar la lucha." 
caballero ha podido prepararse - o la dama ha tenido oportunidad de hallar al caballero más conveniente que pueda luchar por ella y su problema - el combate o la aventura se inicia, y Dios mismo, que es quien decide el desenlace de todas las disputas según la creencia de esta época, revelará al entorno social si la duda acerca del honor era razonable o bien por el contrario carecía de fundamento. De este modo ocurre, por ejemplo, en la obra Iwein. Cuando el caballero Iwein tras incumplir el alejamiento anual socialmente exigido cae en la deshonra, como antes he explicado, arrastra consigo al deshonor a Lunete, criada de su esposa Laudine. Lunete, que había actuado como casamentera entre los dos jóvenes cuando éstos aún no se conocían y había propiciado el matrimonio final, es acusada públicamente de conspirar con un traidor, es decir, con el mismo Iwein, y de desear la perdición de su señora Laudine. De nuevo aquí nos hallamos ante un claro ejemplo en el que el personaje en cuestión actúa de buena fe, pero es víctima de las evidencias que actúan en su contra. Si Iwein hubiese sido realmente un traidor, la intercesión de Lunete ante Laudine para obtener el consentimiento de matrimonio sería imperdonable y, desde luego, sospechosa asimismo de deslealtad consciente. Para dejar patente su inocencia y hallar un caballero que defienda su caso, Lunete dispone de las seis semanas o los cuarenta días preceptivos. El caballero por ella elegido, que cuenta con tiempo idéntico para preparar su aventura, resulta ser el mismo Iwein, quien, al luchar por el honor de Lunete está salvando el suyo propio, pues sólo demostrando no ser un traidor él mismo podrá el joven liberar a Lunete de las graves acusaciones que pesan sobre ella. Puesto que, en realidad, ambos personajes eran inocentes de los crímenes de los que se les acusaba, al final de la historia Dios decide en favor de ambos permitiendo que Iwein venza en su combate, final en el que confiaba el caballero fielmente:
"ouch hete mîn her Îwein
grôzen trôst zuo den zwein,
daz got und ir unschulde
den gewalt niene dulde
daz mi iht misseginge
und daz in ouch vervienge
der lewe sîn geverte
daz er die maget ernerte."

(HARTMANN, 1982: 5167-5174) ${ }^{9}$

Aquí, siendo la inocencia de los personajes patente al lector desde el principio, sólo queda que el entorno social de ambos ratifique este hecho. En los cuarenta días que se le otorgan a Lunete, ella logra hallar al caballero más conveniente para ella, Iwein, el causante de su desgracia.

Los mismos cuarenta días antes mencionados les son concedidos por el rey Arturo asimismo a dos jóvenes hermanas en disputa por una herencia para que hallen al caballero que las represente, puesto que ellas mismas, por tratarse sólo de débiles mujeres, no pueden hacerlo. Aunque el problema entre ambas es fundamentalmente material, no obstante en realidad subyace a él una cuestión de honor. Cuando, tras el fallecimiento del padre de

\footnotetext{
9 "Mi señor Iwein tenía gran confianza en estas dos cosas: que el señor y su inocencia no tolerarían esa crueldad. Confiaba en que nada saldría mal, y que conservarían la vida ambos y él salvaría a la doncella.”
} 
ambas, la hermana mayor intenta quedarse con sus posesiones al completo y despojar a la menor de lo que le corresponde, ésta, de corazón bondadoso, decide no consentir esta afrenta no por los bienes en sí de los que carecerá, sino porque la pérdida de todas esas riquezas suponen también una privación considerable de honor:

"swester, dû bist mir
ze ungnaediges muotes,
wil dû mich mînes guotes
und mîner êren behern.
Des wil ich mich mit kampfe wern"

(HARTMANN, 1982, vv. 5644-5648) ${ }^{10}$

Dado que se ha cuestionado aquí el derecho de la hermana menor a disfrutar de ciertas posesiones de su padre, con ello, se ha puesto en peligro su honor, pues uno de los atributos indispensables en la verdadera dama es la riqueza material. Negando sus derechos sobre ésta, tácitamente se la está rebajando e insinuando con ello que no es una verdadera dama. En esta duda acerca del honor, las seis semanas son de nuevo el plazo apropiado, cuarenta días en los que la hermana mayor, ha de demostrar que, en efecto, la menor no merece los bienes que ambiciona y la menor por el contrario deberá hacer ver que ciertas riquezas de su padre le pertenecen. Dado que no existe en la sociedad cortesano - caballeresca otro modo mejor de zanjar las disputas como ésta que el combate, cada una de las hermanas deberá hallar, en el plazo fijado por el rey, a un caballero que sepa aceptar su defensa y luchar por su honor.

También en la versión de Tristan de Ulrich von Türheim, - la antes mencionada pertenecía a Heinrich von Freiberg - se alude a los cuarenta días como lapso temporal oportuno para organizar la defensa de ese honor quedado en entredicho. El honor cuestionado es aquí de nuevo el de Tristan. Cuando Isolde Manos Blancas, esposa de Tristan, revela a su hermano Kaedin que aún sigue siendo doncella tras más de un año de matrimonio, éste se sorprende muchísimo. Kaedin, que tiene en muy alta estima a su cuñado, al que admira enormemente por su gran valía como caballero, no se atreve a castigar de inmediato a Tristan, en cuya integridad confía en el fondo. Es por ello por lo que le ofrece seis semanas de plazo para preparar su defensa y aportar alguna explicación de su anómalo comportamiento. Tristan, consciente de que su honor peligra gravemente, decide en ese momento revelarle a Kaedin toda la verdad, y, confesando su amor por la mujer de su tío, la otra Isolde, emplea los cuarenta días de los que dispone en mostrarle a Kaedin los muchos encantos de su amante y hacerle comprender con ello por qué su esposa aún conserva la virginidad. Para Kaedin, al final convencido de la inferioridad de la esposa de Tristan, que es su propia hermana, frente a la primera Isolde, tal explicación le parecerá satisfactoria, restituyéndose con ello el tambaleante honor de Tristan.

Cuando las acusaciones son tan serias que pueden dar lugar a la pérdida irreversible del honor del personaje en cuestión, y defender el prestigio social requiere un cierto esfuerzo, se necesitan como mínimo cuarenta días para prepararse adecuadamente. Hay ocasiones,

10 "Hermana, mantienes conmigo una actitud muy deshonrosa. Como deseas quitarme mis bienes y mi honor he de defenderme mediante la lucha." 
sin embargo, en las que el honor del caballero no peligra, es decir, no hà sido cuestionado, pero de igual manera ha de quedar públicamente demostrado, o, mejor dicho, confirmado. En este caso, los cuarenta días se reducirán a sólo catorce, en los que el caballero deberá preparar una nueva aventura y demostrar así que aún sigue siendo arrojado e intrépido a pesar de hallarse retirado de la vida activa o en la que tendrá oportunidad de poner de relieve cualquier otra de las muchas virtudes con las que debe contar el verdadero caballero cortesano.

Así, por ejemplo, el rey Arturo, cuyo honor está por encima de toda duda, considera oportuno dejar transcurrir en la obra Iwein precisamente dos semanas antes de acudir en defensa del honor de su caballero Kalogreant, que ha sido vencido en combate, decisión que a la corte le parece "rîterlich und guot-caballerosa y buena- (HARTMANN, 1982, v. 905)

Catorce días son asimismo los que emplea Iwein en dedicarse a la aventura cuando consigue recuperar su cordura. Pero, más interesante será aquí no obstante que esos mismos días serán empleados también en poner de relieve otras virtudes caballerescas que van más allá de la osadía o el afán de aventuras. Así, por ejemplo, en la novela Erec de Hartmann von Aue, el enano Guivreiz, dueño del castillo de Penefrec, acoge al joven Erec, protagonista de la obra, en su hogar y le ofrece los más costosos placeres, haciendo gala de su generosidad y su hospitalidad, dos de las virtudes fundamentales en un caballero cortesano:

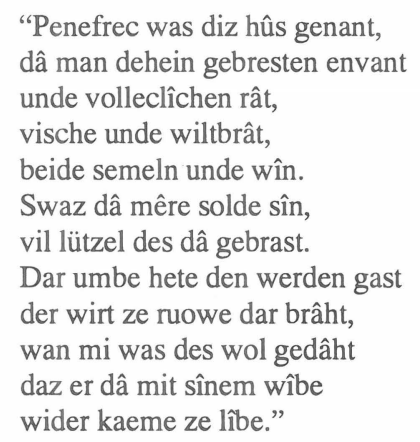

(HARTMANN, 1972: 7188-7199)

Erec, que es tratado a cuerpo de rey, se alojará en el castillo de su amigo durante catorce días, antes de volver a retomar su viaje. Guivreiz, que le acoge durante todo ese tiempo cuidándole inmejorablemente, se perfilará así como uno de los más valiosos caballeros del entorno cortesano.

También Iwein descansa de una de sus aventuras en un castillo cuyo dueño le ofrece hospitalidad y comodidades durante catorce días. Ya el recibimiento que se le hace a Iwein cuando se acerca al castillo es fiel reflejo de la condición del amo:

\footnotetext{
"dô sach er engegen mi gàn

rîter unde knehte,

die in nâch sînem rehte

enpfiengen unde gruozten
} 
und mi vil gerne buozten

kumber unde sîne nôt, als in ir herre gebôt, der selbe engegen ime gienc und in vroelîch enpfienc und schuof mi selhen gemach daz er wol an den werken sach daz sîn wille und sîn muot was reine unde guot"

(HARTMANN, 1982, vv. 5592-5604)

En ese honor demostrado influyen notablemente los catorce días de cuidados que recibe Iwein, las mismas jornadas que emplea el rey Arturo para demostrar su generosidad cuando, con motivo de los esponsales del caballero Erec organiza una fiesta que se prolongará durante todo ese tiempo y en la que

"si wurden alle sô gewert
des waetlîch nimmer mêre ergât.
Beide ros unde wât
gap man der swachen diet
die vor nieman beriet.
Alsô wart daz wol behuot
daz dâ nieman umbe guot
dem anderen nît truoc:
man gap in allen genuoc.
Dâ enwart nieman geschant.
Man gap in allen zehant.
Emphâhens zeran in nie
unz daz diu hôchzît zegie,
unz an den vierzehenden tac.

(HARTMANN, 1972, vv. 2181-2194) $)^{11}$

Pero aún más lejos puede llegar el anfitrión para mostrar su hospitalidad, generosidad, y también humildad y alegría por la visita. Cuando el visitante es conocido y esperado, es decir, ha enviado, previamente a su llegada, a un mensajero que anuncia la inminencia de ésta, el anfitrión, si se encuentra especialmente feliz y desea subrayar lo honrado que se siente por lo ilustre de la visita, sale al encuentra del caballero que se aproxima. Aquí, en las narraciones cortesano - caballerescas, no se contempla curiosamente una distancia local que pudiera llegar a resultar prudente, sino que de nuevo se habla de alejamiento temporal. El rey Lac, por ejemplo, padre de Erec, cabalga durante tres días para darle la bienvenida a su hijo, cuando se le comunica que éste se aproxima. Con la impaciencia que muestra por abrazar al joven Erec cuanto antes posible, no sólo está expresando su amor por su hijo, además, revela la alegría que siente por verlo ya convertido en un caballero meritorio de tales honores. Esos mismos días emplean los caballeros de Erec para acercarse a su amo,

11 “Todos fueron honrados tanto / Que era imposible recibir más / Caballos y vestiduras / les donaron al pueblo empobrecido / Por el que nadie se había preocupado con anterioridad / Así se preocuparon / de que, a causa de sus posesiones, / no tuvieran envidia los unos de los otros / Todos recibieron suficiente / Ninguno habría de avergonzarse / Todos recibieron igual / y los regalos no se acabaron / hasta el fin de la fiesta / A los catorce días" 
cuando, al final de la obra y tras múltiples vivencias, Erec, una vez recuperado su honor, retorna al hogar.

Pero no sólo la duración y los plazos - su mantenimiento o incumplimiento - pueden influir seriamente sobre el honor caballeresco. Igualmente será relevante la organización diaria del tiempo del caballero. Así, se considera esencial que el caballero se dedique a las labores propias de su estado, cual de si un trabajo firme se tratase. El caballero, que cumple con una labor social protegiendo viudas, huérfanos y demás necesitados, cuenta así con una especie de jornada laboral que ha de iniciarse al amanecer y prolongarse hasta bien entrada la noche. Con frecuencia, los madrugones de los más valientes caballeros son destacados por los autores. De Erec, por ejemplo, se dice que despertaba al alba, aun cuando hubiese estado luchando hasta bien entrada la noche, porque deseaba acudir a misa, hecho que el autor subraya como caballeresco:

"morgen als ez tagete,

Êrec ûf machte sich.

Sîn êrste vart was ritterlich:

zuo der kirchen er gie"

(HARTMANN, 1972, vv. 2487-2489) $^{12}$

De este modo, llama poderosamente la atención que, cuando Erec se desposa con la bella Enite, aún continúe acostado a plena luz del día y asista con desgana al servicio religioso, hechos estos que provocan la crítica social y el deshonor de Erec. No es hasta casi el final de la obra, cuando lentamente Erec ha vuelto a recuperar su honor, cuando el autor indica cómo el ya de nuevo valeroso caballero retoma las costumbres adecuadas, y por primera vez desde hacía mucho tiempo, madruga para oír misa, esta vez acompañado de su esposa Enite.

$\mathrm{Al}$ amanecer también sale, en la obra Iwein, el primo de éste, Kalogreant, en busca de aventuras. Y cuando ha de salvar a la criada Lunete, Iwein le promete presentarse al combate a primera hora de la mañana. Cuando Iwein pierde su honor y se vuelve loco, adoptando las costumbres de un animal, el autor revela cómo dedicaba también las horas diurnas a dormir, lo cual es interpretado como un signo de su irracionalidad. También Daniel von dem blühenden Tal, intrépido caballero protagonista de la obra del mismo nombre de Der Stricker, siempre se levanta al alba y en la obra Parzival su padre Gahmuret siempre veía salir el sol mientras se preparaba para cumplir con alguna misión. Parzival, uno de los más valientes caballeros, llegará incluso aún más lejos. No sólo cumple a la perfección con las obligaciones matutinas del caballero, sino que incluso apenas puede aguardar que transcurre la noche y espera impaciente la llegada del día para poder continuar su camino:

"Die naht beleip der knappe dâ: man sach in des morgens anderswâ.

Des tages er kûme erbeite"

(WOLFRAM, 1989: 242-244) $)^{13}$

\footnotetext{
12 "Por la mañana, cuando amanecía, Erec se ponía en camino. Su primer camino era caballeroso: se dirigía a la Iglesia"
} 
A veces, el joven incluso antes aún del alba ya emprende la marcha. $Y$ al igual que se inicia al amanecer, la actividad del caballero no ha de darse por concluida sino al anochecer. En varias ocasiones, Erec debe aplazar la conclusión de su combate hasta la mañana siguiente, pues la falta de visibilidad impide ya una continuación. También Iwein lucha frecuentemente "unz daz diu naht ane gienc / und ez diu vinster undervienc." (HARTMANN, 1982: 7347-7348), hasta que se acercó la noche, y la oscuridad los atrapó, siendo esta continuidad habitual en la mayor parte de los caballeros.

Aunque sin duda podría hablarse mucho más de la influencia del tiempo sobre el honor del caballero cortesano - caballeresco, no obstante quiero concluir ahora lo que no pretendía ser más que un breve acercamiento a este tema. La frecuencia con la que aparecen una y otra vez los mismos espacios temporales a lo largo de diferentes obras cortesanas refleja la importancia que se debe conceder a uno de los aspectos más olvidados de este mundo sólo en apariencia atemporal. La sociedad cortesano - caballeresca fija unas normas muy estrictas a aquellos que desean ser considerados miembros de ello por pleno derecho. Un buen caballero ha de poseer virtudes caballerescas destacadas como, por ejemplo, constancia, bondad, humildad, fortaleza, castidad, fidelidad, moderación, valentía, alegría, belleza, inteligencia, generosidad, hospitalidad, compasión, riqueza material, lujo, ciertas habilidades musicales, temor a Dios, servicio a la Dama, fidelidad a su señor, y, no debe faltar tampoco, tal como he intentado demostrar hoy, un cierto sentido del tiempo.

\section{BIBLIOGRAFÍA:}

ARENTZEN, J. ; RUBERG, U. (eds.) (1987), Die Ritteridee in der deutschen Literatur des Mittelalters. Eine kommentierte Anthologie, Darmstadt

HARTMANN VON AUE (1972), Erec ,Frankfurt

HARTMANN VON AUE, (1982) Iwein, Stuttgart

HEINRICH VON FREIBERG (1877), Tristan, Leipzig; Neudr. Amsterdam 1966

TOMASEK, T. (1985), Die Utopie im Tristan Gottfrids von Strassburg, Tübingen

WOLFRAM VON ESCHENBACH (1989), Parzival, Stuttgart

13 "Durante la noche permaneció allí el escudero, pero por la mañana ya se encontraba en otra parte. Apenas podía esperar la llegada del amanecer." 
